\title{
PBAT/TPS Composite Films Reinforced with Starch Nanoparticles Produced by Ultrasound
}

\author{
Normane Mirele Chaves da Silva, ${ }^{1}$ Paulo Romano Cruz Correia, ${ }^{2}$ \\ Janice Izabel Druzian, ${ }^{2}$ Farayde Matta Fakhouri, ${ }^{3}$ Rosana Lopes Lima Fialho, ${ }^{1}$ \\ and Elaine Christine Magalhães Cabral de Albuquerque ${ }^{1}$
}

\author{
${ }^{1}$ Polytechnic School, Federal University of Bahia, Salvador, BA, Brazil \\ ${ }^{2}$ Department of Bromatological Analysis, College of Pharmacy, Federal University of Bahia, Salvador, BA, Brazil \\ ${ }^{3}$ Faculty of Engineering, Federal University of Grande Dourados, Dourados, MS, Brazil
}

Correspondence should be addressed to Normane Mirele Chaves da Silva; normanechaves@yahoo.com

Received 18 July 2017; Revised 3 November 2017; Accepted 13 November 2017; Published 11 December 2017

Academic Editor: Eliane Espuche

Copyright (c) 2017 Normane Mirele Chaves da Silva et al. This is an open access article distributed under the Creative Commons Attribution License, which permits unrestricted use, distribution, and reproduction in any medium, provided the original work is properly cited.

\begin{abstract}
The objective of the present work was to study the incorporation of starch nanoparticles (SNP) produced by ultrasound in blends of poly(butylene adipate-co-terephthalate) (PBAT) and thermoplastic starch (TPS). The films were produced by extrusion using varying percentages of SNP $(1,2,3,4$, and $5 \% \mathrm{w} / \mathrm{w})$. The SNP were prepared in water without the addition of any chemical reagent. The results revealed that ultrasound treatment results in the formation of SNP less than $100 \mathrm{~nm}$ in size and of an amorphous character and lower thermal stability and low gelatinization temperature when compared with cassava starch. Scanning electron microscopy (SEM) showed that films presented some starch granules. The relative crystallinity (RC) of films decreases with increasing concentration of SNP. The addition of SNP slightly affected the thermal degradation of the films. The DSC results showed that the addition did not modify the interaction between the different components of the films. Mechanical tests revealed an increase in Young's modulus (36\%) and elongation-at-break (35\%) with the incorporation of $1 \%$ SNP and this concentration reduced the water vapor permeability (53\%) and significantly decreased the water absorption of the films, demonstrating that low concentrations of SNP can be used as reinforcement in a polymeric matrix.
\end{abstract}

\section{Introduction}

Severe environmental problems, including the increasing difficulties of waste disposal and the deepening threat of global warming (due to carbon dioxide released during incineration) caused by the nonbiodegradability of a number of polymers, have raised concerns all over the world [1]. To overcome some of these problems, several studies have focused on the development of biodegradable plastic for the development of sustainable packaging materials made from starches, agroresources, and copolyesters [2].

Among the biodegradable polymers made from renewable resources, starch is probably the most renewable naturally biodegradable polymer source because it is versatile, cheap, and abundant [3]. It shows compatibility with extrusion processes used in the manufacture of conventional films and in the presence of a plasticizer it produces a material with thermoplastic characteristics, known as thermoplastic starch (TPS) $[4,5]$. However, the hydrophilic nature of thermoplastic starch and its fragility and high sensitivity to moisture limit its use as a packaging material. Besides this, the retrogradation and crystallization of the mobile starch chains change its mechanical and barrier properties [6]. As a result, TPS is often blended with other polymers, such as poly(butylene adipate-co-terephthalate) (PBAT) and biodegradable aliphatic-aromatic copolyester, which combines biodegradability with other desirable physical properties [7]. However, it is expensive to produce, which limits its use on a wider scale [8]. When starch and PBAT are mixed on the other hand, the cost is lower and 
their degradability properties are increased. Moreover, the incorporation of other additives, such as a plasticizer, compatibilizers, and nanocomposites, may also improve mechanical and barrier properties of the films. Nanofibers and nanocrystals (nanowhiskers) of cellulose are among additives/nanomaterials widely used as reinforcement in films of different polymeric matrices [9-11]. Starch nanoparticles can be also used as reinforcement. These may be produced by different methods (acid hydrolysis, mechanical, regeneration, and others) [12-14].

Acid hydrolysis has been widely used for the preparation of starch nanoparticles (SNP). However, using this method, the recovery yield is relatively low, in addition to generating waste with a negative environmental impact, which hinders any industrial application of SNP [15]. For these reasons, many researchers have been examining other procedures with physical treatments or a combination of different methods [16]. The ultrasound technique is a new method for producing SNP involving a physical-disintegration process. There is no need to do any chemical treatment or to add any chemical reagent and it is an environmentally friendly approach which is arousing increasing interest [12]. This method has been widely used to produce SNP by many researchers [17-20]. In these, SNP has been used as a reinforcing phase in a polymeric matrix to improve the mechanical and barrier properties of films [21].The work in [22] studied the influence of the addition of SNP produced by gamma radiation into a PBAT/TPS blend based film. These authors reported that the presence of SNP affects the rate of biodegradability and the mechanical properties of the films. It is important to highlight that research into the production of biodegradable polymeric films by extrusion with nanoparticles is recent and many approaches are being used.

Thus, the aim of this study was to produce and characterize films by thermoplastic extrusion of PBAT/TPS incorporated with different concentrations $(1-5 \% \mathrm{w} / \mathrm{w})$ of SNP produced with ultrasound.

\section{Materials and Methods}

2.1. Materials. The cassava starch (CS) was kindly donated by Cargill Agrícola S.A. The PBAT with the commercial name of Ecoflex-F was acquired from BASF, and commercial glycerol (Dinámica, Brazil) was used as a plasticizer. The citric acid (Vetec Quimica Fina Ltda) and the stearic acid (Dinámica, Brazil) were used as compatibilizer agents.

2.2. Starch Nanoparticles (SNP) Production. Starch nanoparticles (SNP) were produced according to the method adapted from [17]. The starch suspension $(50 \mathrm{~mL})$ with a solid content of $1.5 \mathrm{w} / \mathrm{t} \%$ was sonicated in a Qsonica ultrasound (model Q55, USA) at $50 \mathrm{~W}$ for 75 minutes. Then, the colloidal suspension was frozen and dried by freezing (lyophilization).

2.3. Films Production. The blends (films) were processed by the thermoplastic extrusion processusing a laboratory twinscrew extruder (model AX16DR, AX Plásticos, Brazil) with a screw diameter $(D)$ of $16 \mathrm{~mm}$ and length to diameter ratio
$(L / D)$ of $40 \mathrm{D}$. Glycerol was used as the plasticizer, and citric and stearic acids were used as compatibilizers.

The films were prepared according to the method adapted from [23] and following three steps. Initially, the glycerol $(7.0 \mathrm{w} / \mathrm{w} \%)$ compatibilizers citric acid $(0.6 \mathrm{w} / \mathrm{w} \%)$ and stearic acid $(0.3 \mathrm{w} / \mathrm{w} \%)$ with or without SNP were mixed with starch and homogenized. The concentration of SNP used was 1, 2, 3, 4 , and $5 \mathrm{w} / \mathrm{w} \%$ of the matrix.

In the second stage, the PBAT/TPS blends in the ratio of $70 / 30$ were prepared. Pellets were obtained by extruding from the mixtures in a twin extruder. The screw speed was $44 \mathrm{rpm}$ and the barrel zone temperature profile was set at $80 / 120 / 130 / 130 / 140 / 140 / 140 / 145^{\circ} \mathrm{C}$ for zones from 1 to 8 , respectively.

In the last stage, the pellets were processed to obtain the final material in the form of films; the same parameters (screw speed and zone temperature) were used, with the inclusion of the former matrix of the films which was kept at $130^{\circ} \mathrm{C}$.

The corresponding films were labelled $X X / Y Y / Z$, where $X$ is the proportion of PBAT, $Y$ is the proportion of starch in the blend, and $Z$ is the w/w\% of SNP. All of the samples were conditioned at a $53 \pm 2 \%$ relative humidity and $25 \pm 2^{\circ} \mathrm{C}$ before the analysis.

\subsection{Starch Nanoparticles (SNP) and Polymeric}

\section{Films Characterization}

2.4.1. Mean Diameter, Polydispersity Index, and SNP Zeta Potential. The mean diameter and size distribution of colloidal suspension were determined by dynamic light scattering using Zetasizer Nano ZS equipment (Malvern Instruments, UK). The reported values are the average of the three measures.

2.4.2. Morphology. The morphology of the SNP was evaluated using the transmission electron microscopy (TEM) through the negative contrast technique, carried out in a $120 \mathrm{kV}$ Tecnai G2-12 Spirit (FEI, Netherlands) transmission electron microscope. The suspension was deposited on a carbon-coated grid and after around 2 minutes the excess liquid was absorbed with filter paper specifically designed for drying. One drop of $2 \%$ uranyl acetate was deposited over the grid and, after removing the excess dye, the resultant thin film was exposed for drying for later visualization.

The morphological characteristics of the surfaces of films were analyzed with the scanning electron microscopy (SEM) in a Quanta 200 model microscope (FEI, Netherlands). All samples were metalized by deposition of a thin layer of gold in a Quorum $150 \mathrm{R}$ sputter. A $5 \mathrm{Kv}$ tension was used to avoid film degradation.

2.4.3. Crystallinity (XRD). The CS, SNP, and film analyses were carried out using MiniFlex X-Ray Diffractometer (Rigaku, Japan), with a pace of $4^{\circ} / \mathrm{min}$ (SNP) or $2^{\circ} / \mathrm{min}$ (films) and copper radiation $\lambda=1,5433 \hat{\mathrm{A}}$, operating with $40 \mathrm{kV}$ and a flow of $30 \mathrm{~mA}$, scanning between $5^{\circ} \mathrm{C}$ and $40^{\circ} \mathrm{C}$. The relative crystallinity (RC) of the films was quantitatively calculated 
following the method of Nara and Komiya [24], according to the following equation:

$$
\mathrm{RC}(\%)=\frac{\mathrm{Ac}}{\mathrm{Aa}+\mathrm{Ac}},
$$

where Ac is the crystalline area and Aa is the amorphous area on the X-ray diffractogram.

2.4.4. Thermal Analysis. The thermogravimetric analysis (TGA) was made in a Perkin Elmer thermal analyzer, model STA 6000 (USA), assisted by Pyris Series software. In the tests for the CS, SNP and films of about $8 \mathrm{mg}$ in an inert nitrogen atmosphere of $30 \mathrm{~mL} / \mathrm{min}$ were used, with a heat rate of $10^{\circ} \mathrm{C} / \mathrm{min}$, at a temperature interval of 25 to $600^{\circ} \mathrm{C}$.

For the Differential Scanning Calorimetry (DSC), a TA Instruments (USA) calorimeter, model TA 2010 (USA), was used. Approximately $10 \mathrm{mg}$ of preconditioned samples $(60 \%$ $\mathrm{UR}, 25^{\circ} \mathrm{C}$ ) was hermetically sealed in an aluminum crucible to prevent water evaporation during the scan. The CS and SNP samples were heated from 20 to $200^{\circ} \mathrm{C}$ and the sample films were heated from -40 to $200^{\circ} \mathrm{C}$, all at a rate of $10^{\circ} \mathrm{C} / \mathrm{min}$.

2.4.5. Film Thickness. The film thickness was set using a Digimess (Brazil) flat tip digital micrometer (from 0 to $25 \mathrm{~mm}$, with $0.001 \mathrm{~mm}$ resolution) and set by the average of 10 random measures in different parts of an equal sample.

2.4.6. Water Vapor Permeability (WVP). The permeability rate of the water steam and the permeability of the films were carried out by using a modified E96-95 ASTM Standard method (ASTM, 1995). The change in the weight of the cell was plotted as a function of time and the slope of each line was calculated by linear regression. The water vapor transmission rate (WVTR, $\mathrm{g} \mathrm{h}^{-1} \mathrm{~m}^{-2}$ ) was calculated from the slope $(\mathrm{g} / \mathrm{s})$ and the cell area $\left(\mathrm{m}^{2}\right)$. WVP $\left(\mathrm{gmsPa}^{-1}\right)$ was determined using the following equation:

$$
\mathrm{WVP}=\frac{\mathrm{WVP} t \cdot x \cdot S^{-1}}{R 1-R 2},
$$

where WVP is permeability rate of the water steam, $x$ is the film thickness, $S$ is saturation pressure of water steam in work temperature, $R 1$ and $R 2$ are the relative humidities of the air in each of the faces of the sample, $G$ is the mass variation, $t$ is the time, and $S$ is a constant $(2329.69 \mathrm{~Pa})$.

2.4.7. Apparent Opacity. This test was carried out in FEMTO model 700 PLUS (Brazil) spectrophotometer according to [25]. The films were cut into squares and adhered to the inner wall of the bucket in such a way as to be positioned perpendicular to the light beam. The visible light band was scanned at $600 \mathrm{~nm}$ for each film and the opacity was calculated according to the following equation:

$$
\text { opacity }=\frac{A_{600}}{T}
$$

where $A_{600}$ is the absorption at $600 \mathrm{~nm}$ and $T$ is the thickness of the film in $\mathrm{mm}$. The analyses were carried out in triplicate.
2.4.8. Water Absorption Measurement. The samples were cut into pieces of $2 \mathrm{~cm} \times 2 \mathrm{~cm}$ stored at $55 \% \mathrm{RH}$ for 7 days before testing and then dried in the oven at $105^{\circ} \mathrm{C}$ for $24 \mathrm{~h}$. These samples were weighed immediately after being removed from the oven. The water absorption was calculated using the following equation [26-28]:

$$
\text { water absorption }(\%)=\frac{\left(W_{1}-W_{2}\right)}{W_{2}}
$$

where $W_{1}$ is the weight of sample before drying and $W_{2}$ is the weightof sample after drying. All measurements were performed intriplicate.

2.4.9. Mechanical Properties. The films were characterized through traction tests, according to the ASTM Standard method D882-02 (ASTM, 2002). Rectangular proof bodies (with $25 \mathrm{~mm}$ width and $190 \mathrm{~mm}$ length) were acquired and put into a test machine from Emic, model DL 2000 (Brazil), with charge cell of $500 \mathrm{~N}$, at ambient temperature, characterizing the rupture properties and elasticity module.

2.5. Statistical Analysis. The data were analyzed using ASSISTAT software, version 7.7 (Brazil), with the analysis of variance (ANOVA) and Tukey's test at a 5\% significance level.

\section{Results and Discussions}

3.1. SNP Mean Diameter, Size Distribution, and Zeta Potential of SNP. The SNP demonstrated a bimodal distribution with mean diameter $\left(D_{[4,3]}\right)$ of approximately $77.51 \pm 0.77 \mathrm{~nm}$ (93.1\% of the major population). The work in [17] obtained starch nanoparticles produced by ultrasound (75 minutes at $136 \mathrm{~W}$ ) with size distribution ranging from 30 to $100 \mathrm{~nm}$. The mean diameter of the nanoparticles plays an important role in the physical and chemical properties and therefore in their industrial application [29].

The polydispersity index (PDI) values varied between 0.2 and 0.5 . PDI values smaller than 0.5 indicate a relative homogenous dispersion [30]. The work in [20] produced SNP from Araucaria angustifolia by acid hydrolysis and by ultrasound. The authors therein obtained polydispersity index values of 0.380 for nanoparticles produced by ultrasound.

The zeta potential of the SNP was slightly negative $(-8.67 \mathrm{mV})$. This result is consistent with those obtained by [31] that observed zeta potential of $-3 \mathrm{mV}$ for waxy maize using the same technique. The negative surface charges of the starch due to hydroxyl groups present in its structure tend to ionize in water and this may be affected by the sonication [32]. High zeta potential value or its magnitude (negative or positive absolute value) is important as physical stability is an indicator of a colloidal dispersion because great repulsive forces tend to discourage aggregation of the nanoparticles [29]. In this work, the zeta potential values were between $-10 \mathrm{mV}$ and $0 \mathrm{mV}$, and they are considered approximately neutral particles with a tendency for aggregation in water. However, SNP were incorporated into PBAT/starch mixture in powder form and not in aqueous medium to be processed 


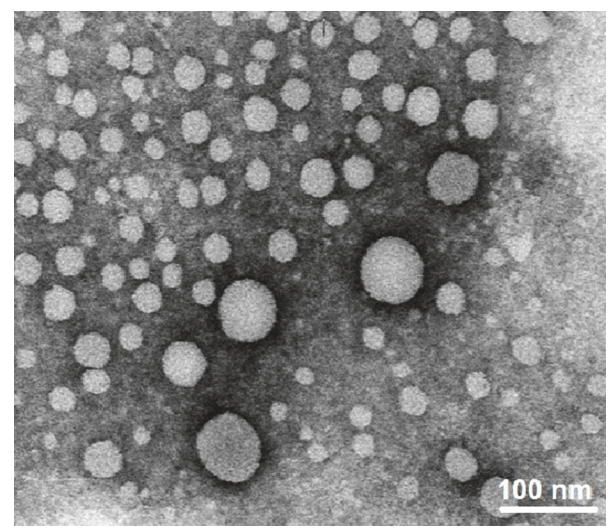

FIGURE 1: SNP images obtained by transmission electronic microscope (TEM). Magnification: 1000x.

by extrusion. As a result, the nanoparticles instability does not affect the processing of the film.

3.2. Morphology. Figure 1 shows the photomicrography of the SNP. It can be observed that the nanoparticles have a roughly spherical morphology and diameters which are smaller than $100 \mathrm{~nm}$. Figure 1 confirms the particle size distribution pattern observed by QELS analysis (major population with mean diameter of $77.51 \pm 0.77 \mathrm{~nm}$ ).

Figure 2 shows the scanning electronic microscopy (SEM) images of the surface of the films. The PBAT film (Figure 2(a)) micrograph shows a homogenous and smooth structure, with the absence of pores and no major defects. In the morphology of the surface of the PBAT/TPS film (Figure 2(b)), a smooth surface can also be seen. However, it is possible to see starch granules that were not completely ruptured during the extrusion process; probably the temperature and the time used were not enough to break all the granules. Despite the starch granules, no cracks in the polymer matrix were found. The same film surface behavior has also been reported by other authors for PBAT/TPS blends in a ratio of $70: 30[22,33,34]$.

The addition of SNP to PBAT/TPS blends (Figures 2(c), 2(d), 2(e), 2(f), and 2(g)) did not affect the film surface.

3.3. Crystallinity: XRD. The X-ray diffraction (XRD) patterns recorded for CS, SNP, and films are shown in Figures 3 and 4 , respectively. The starch granule (which presents a certain degree of molecular organization) is partially crystalline and has a degree of crystallinity ranging from $20 \%$ to $45 \%$. The cassava starch has C-type crystallinity (with characteristics of types $A$ and $B$ ) and diffraction peaks in $2 \theta=15,3^{\circ} ; 17,3^{\circ} ; 18,3^{\circ}$; $22,0^{\circ}$; and $23,5^{\circ}$ [35].

It was also observed that cassava starch has more intense and straight peaks corresponding both to type A crystallinity $\left(2 \theta \sim 15^{\circ}\right)$ and type B crystallinity $\left(2 \theta \sim 17^{\circ}, 18^{\circ}\right.$, and $\left.23^{\circ}\right)$, characterizing type $\mathrm{C}$ crystallinity. Starches are classified as type $\mathrm{A}$, type $\mathrm{B}$, or type $\mathrm{C}$, depending on the type of crystalline structures present in their granules. In type A starch, double helices of chains are densely packed. Type B crystals with a pseudohexagonal system are formed by rather loosely arranged double helices. Type $\mathrm{C}$ is considered as a mixture of forms $\mathrm{A}$ and $\mathrm{B}$. The relative crystallinity for type C starch was $28 \%$.

Analyzing the X-ray diffraction pattern of SNP (Figure 3), it can be seen that the ultrasonication process influenced the crystalline structure of the native starch. The cassava starch processing resulted in a serious disruption of the crystalline structure of clustered amylopectin, leading to nanoparticles with low crystallinity or an amorphous character. This corroborates other research results reported in theliterature [1720].

The X-ray diffraction patterns of the films with and without SNP are shown in Figure 4 . All the X-ray diffraction patterns showed peaks at $2 \theta=17.5^{\circ}, 20.5^{\circ}$, and $23.2^{\circ}$, attributed mainly to PBAT $[36,37]$.

The level of the relative crystallinity of the films based on the peak intensity ranged from $32 \%$ (5\% of SNP) to $42 \%$ (PBAT/TPS). The addition of starch to the PBAT matrix increased the crystallinity, suggesting amylose recrystallization during the extrusion process [38]. The crystallinity associated with the recrystallization of the amylose which occurs may be because during the extrusion process an amylose (amorphous portion of the native starch) can be crystallized and this structural change can increase the degree of crystallinity [36-38].

The PBAT/TPS/SNP films showed a decrease in the degree of crystallinity when compared to PBAT/TPS films. This may be associated with the amorphous character of the nanoparticles (as shown in Figure 3).

3.4. Thermal Analysis. The thermal stability of CS and SNP is shown in Figure 5. Thermogravimetric (TG) curves show two-step degradation processes. For starch, there is a mass decrease in the initial stage $\left(60-118^{\circ} \mathrm{C}\right)$ corresponding to water evaporation. In the second stage $\left(280-356^{\circ} \mathrm{C}\right)$, a mass loss of $77.4 \%$ corresponding to thermal decomposition of the sample can be seen. For SNP, there is an initial mass loss of $8.97 \%\left(40-93^{\circ} \mathrm{C}\right)$ followed by second stage of mass loss $\left(269-352^{\circ} \mathrm{C}\right)$ corresponding to $76.8 \%$.

It can be also observed from Figure 5 that SNP began to lose weight at a temperature lower than that of native starch. The lower thermal stability of this material can be related to a high number of hydroxyl groups on their surface, through which thermal degradation starts $[39,40]$.

The TG curves of the films are shown in Figure 6. The PBAT film presents a single degradation process with an initial degradation temperature of $352^{\circ} \mathrm{C}$ and final degradation peak of $436.85^{\circ} \mathrm{C}$, similar to those obtained in the literature $[33,34]$.

In case of PBAT/TPS films and PBAT/TPS with SNP, the thermogram shows two-step degradation processes. The initial step of degradation at $280^{\circ} \mathrm{C}$ corresponds to the water loss and the step at $345^{\circ} \mathrm{C}$ corresponds to the starch and glycerol decomposition [41]. The maximum degradation of PBAT was noticed at around $430^{\circ} \mathrm{C}$, which was marginally reduced to $400^{\circ} \mathrm{C}$ in PBAT/TPS and PBAT/TPS/SNP biodegradable blends. This is probably due to the hydrophilic nature of TPS and lower thermal stability of the SNP, as shown in Figure 5. 


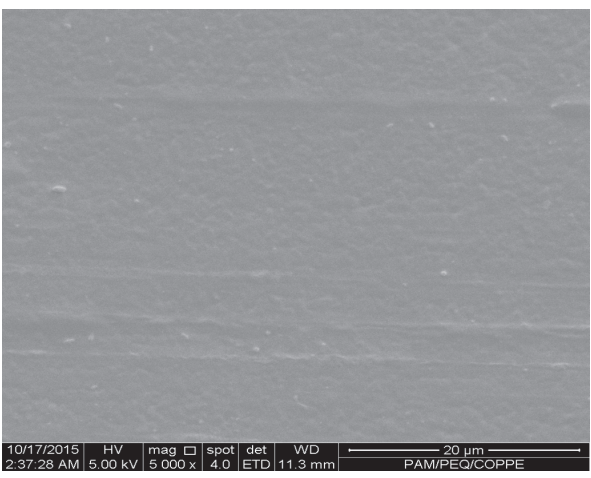

(a)

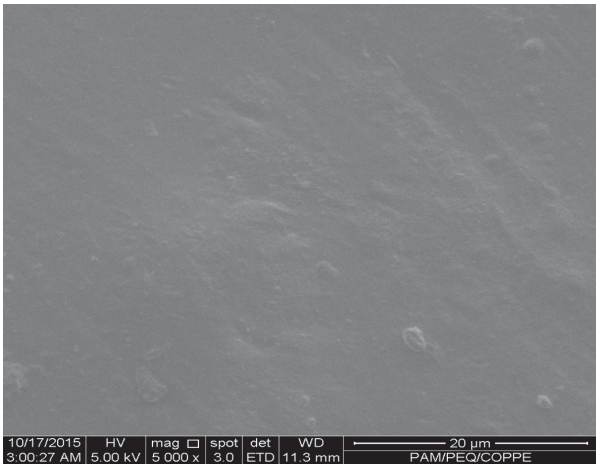

(c)

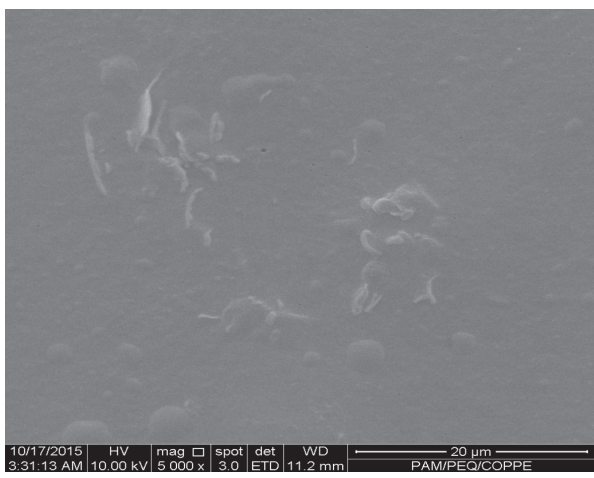

(e)

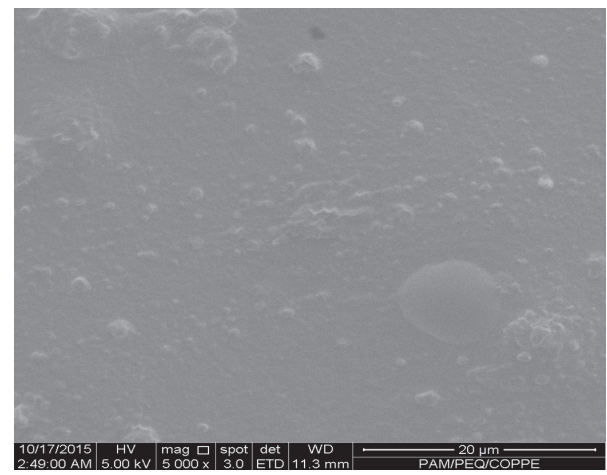

(b)

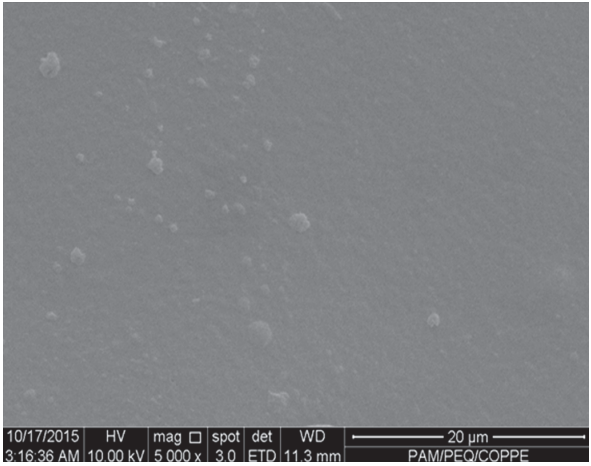

(d)

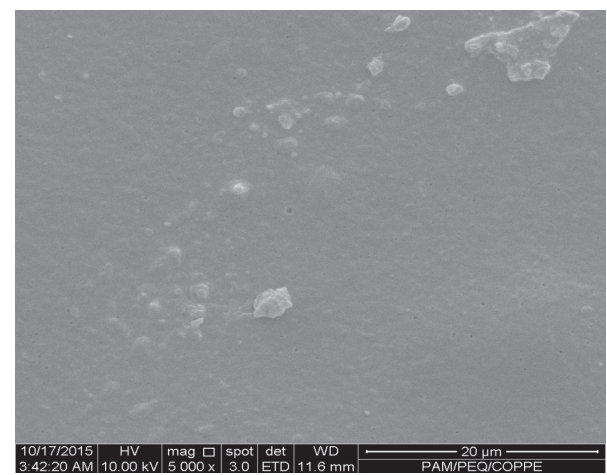

(f)

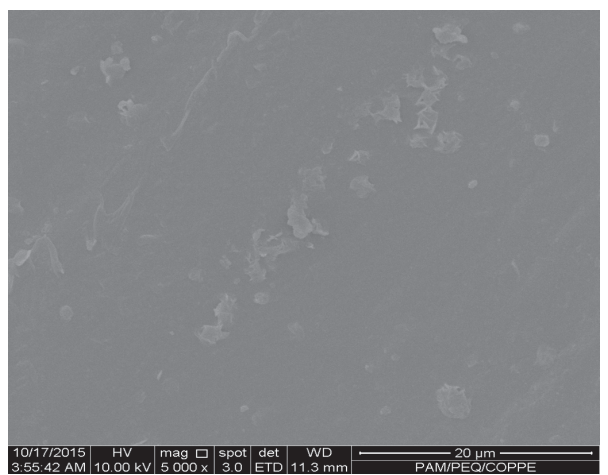

(g)

Figure 2: SEM of the surface of the films. PBAT (a), PBAT/TPS (b), 70/30/1\% (c), 70/30/2\% (d), 70/30/3\% (e), 70/30/4\% (f), and 70/30/5\% (g). Magnification: 5000x. 


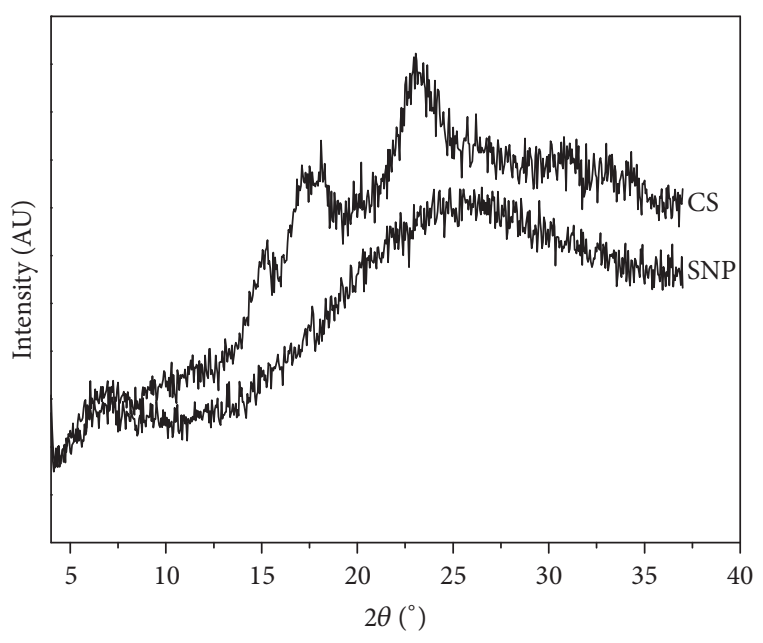

FIGURE 3: X-ray diffraction patterns for cassava starch (CS) and starch nanoparticles (SNP).

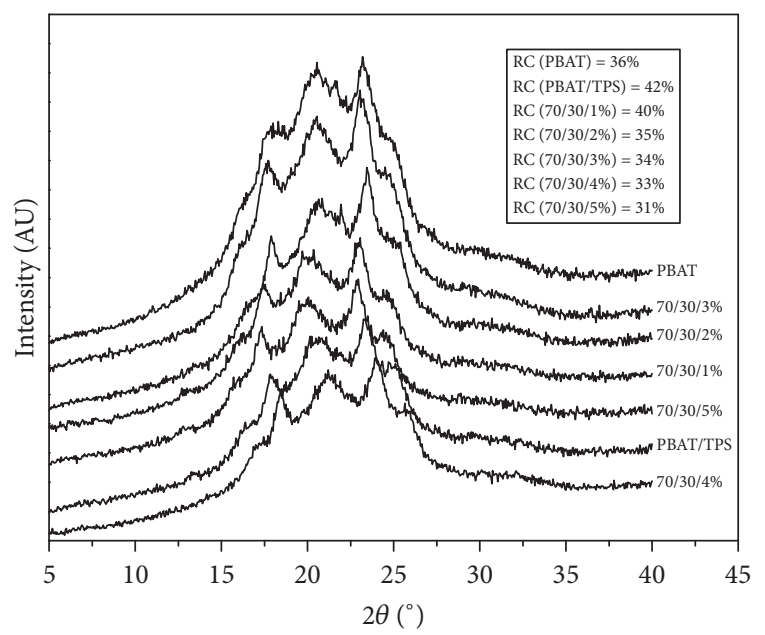

FIGURE 4: X-ray diffraction patterns and relative crystallinity (RC) of the films.

3.5. Differential Scanning Calorimeter (DSC). The curves obtained through the analysis by DSC of CS, SNP, and the films are presented in Figures 7 and 8, respectively.

In the DSC analysis of starch and SNP, the presence of only one endothermic event in each one of the curves $\left(0-200^{\circ} \mathrm{C}\right)$ can be seen. For SNP, the event occurred at $43.58^{\circ} \mathrm{C}$ and for CS it occurred at $64.50^{\circ} \mathrm{C}$, probably associated with gelatinization temperature. SNP presented a lower gelatinization temperature due to its amorphous character (Figure 3), as gelatinization tends to occur in the amorphous regions and as a result hydrogen bonding is weakened in this region.

There is no detailed description about the gelatinization temperature of starch nanoparticles produced by ultrasound in the literature. The work in [42] claims that gelatinization related to SNP can be affected by experimental conditions of ultrasonication, starch type, and composition. The work in $[43,44]$ showed that gelatinization temperature of corn

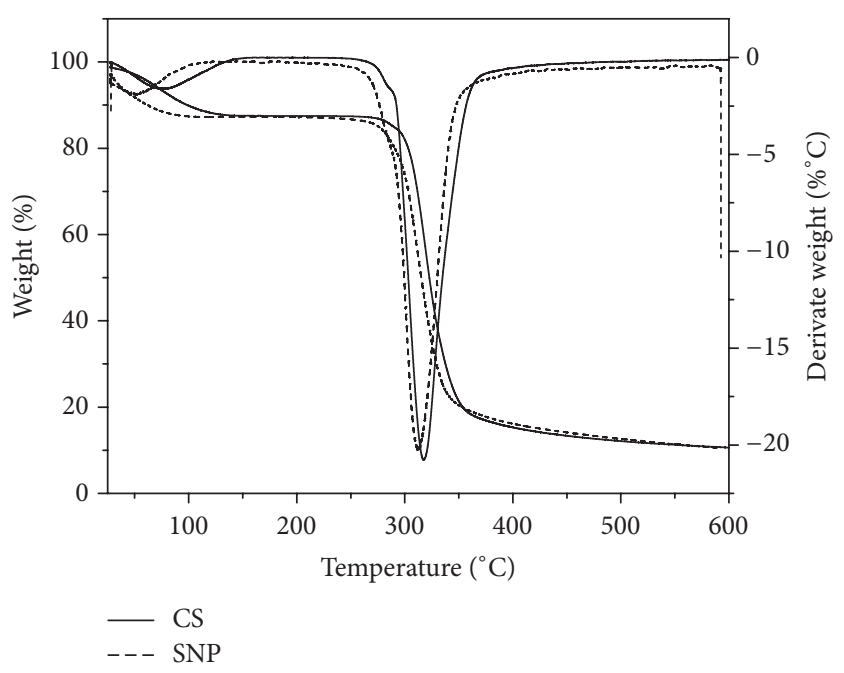

FIgURE 5: Thermogravimetric analysis (TG) and derivative thermogravimetric (DTG) curves of cassava starch (CS) and starch nanoparticles (SNP).

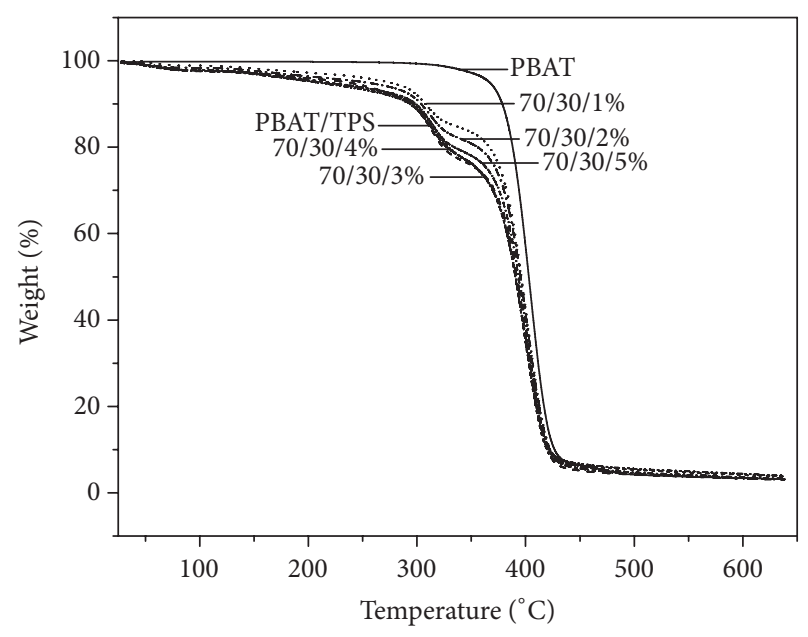

FIGURE 6: Thermogravimetric analysis of the films.

starch nanoparticles, produced using the same technique, was between $66.44^{\circ} \mathrm{C}$ and $78.39^{\circ} \mathrm{C}$.

DSC curves of films are shown in Figure 8. The PBAT film presents a glass transition temperature $\left(T_{\mathrm{g}}\right)$ of around $-33.31^{\circ} \mathrm{C}$. Similar results were obtained by other authors [34, $45,46]$. The DSC curves had two additional peaks related to melting temperatures, $T_{\mathrm{m} 1}$ and $T_{\mathrm{m} 2}, 53^{\circ} \mathrm{C}$ and $130^{\circ} \mathrm{C}$, respectively [47]. These two endothermic events are related to the two segments that make up the chemical structure of PBAT, which are butylene terephthalate (BT) and butylene adipate (BA) segment. The first $\left(T_{\mathrm{m} 1}\right)$ refers to the presence of a soft crystal lattice containing mainly butylene adipate segment and the second $\left(T_{\mathrm{m} 2}\right)$ to the fusion of butylene terephthalate crystals [22].

All the films, PBAT/TPS and PBAT/TPS/SNP, had similar profiles $\left(T_{\mathrm{g}}\right.$ and $\left.T_{\mathrm{m} 2}\right)$ to PBAT film. However, a displacement peak in $T_{\mathrm{m} 1}$ towards higher temperatures (around $60^{\circ} \mathrm{C}$ ) was 


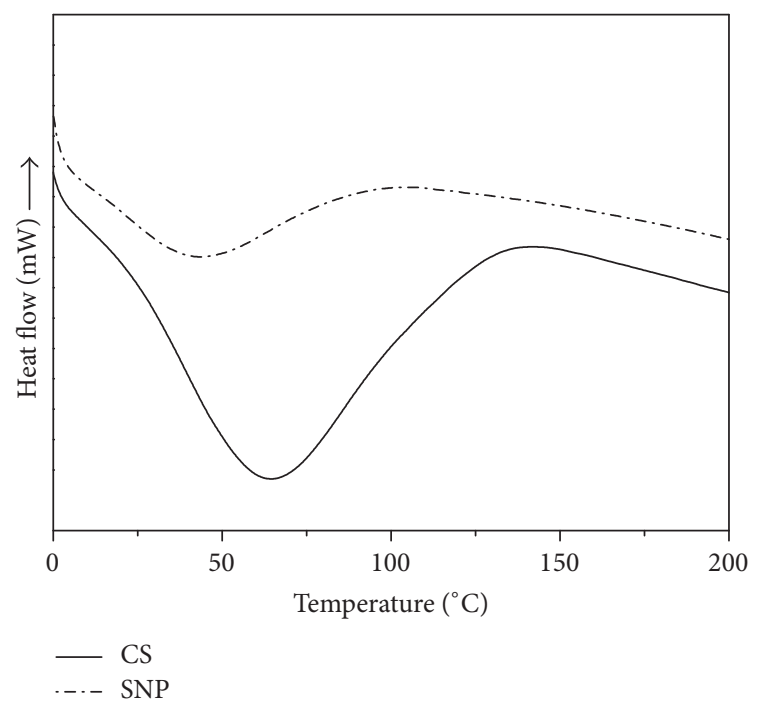

Figure 7: Differential thermal analysis of cassava starch (CS) and starch nanoparticles (SNP).

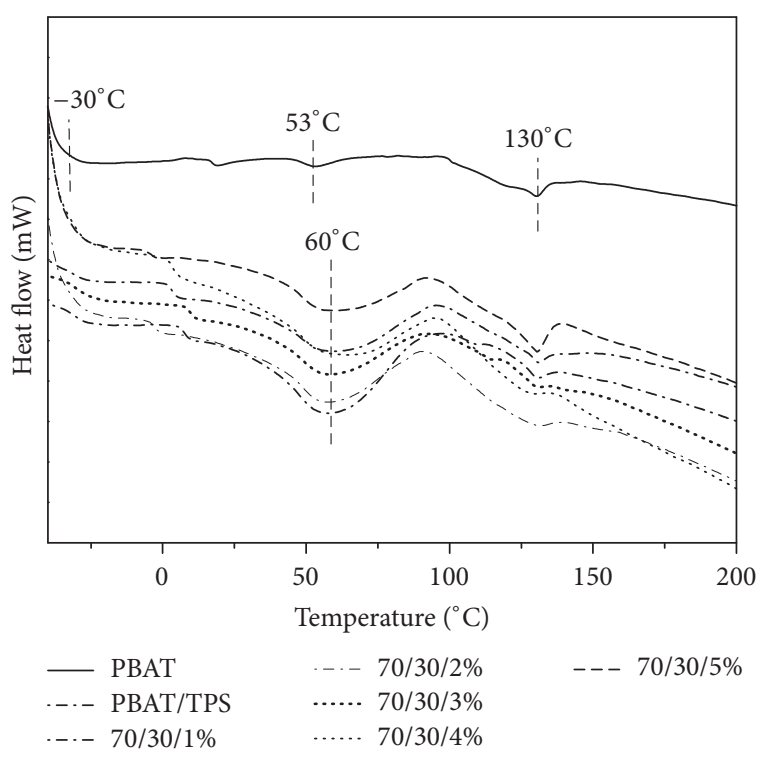

FIGURE 8: Differential thermal analysis for films.

observed when compared to the PBAT film. This indicates moderate interaction between the PBAT matrix and TPS [34].

3.6. Thickness, Water Vapor Permeability (WVP), and Opacity. In Table 1 , the results of the thickness, WVP, and opacity of the films are presented. With regard to thickness, it can be observed that there were no significant differences between the films $(p>0.05)$.

The water vapor barrier properties of a polymer are very important for estimating and predicting the shelf-life of a product package. Food packaging barrier requirements are related to the product characteristics and the intended enduse application. Water vapor is crucial as it alters the sensory, physicochemical, and microbiological characteristics of food

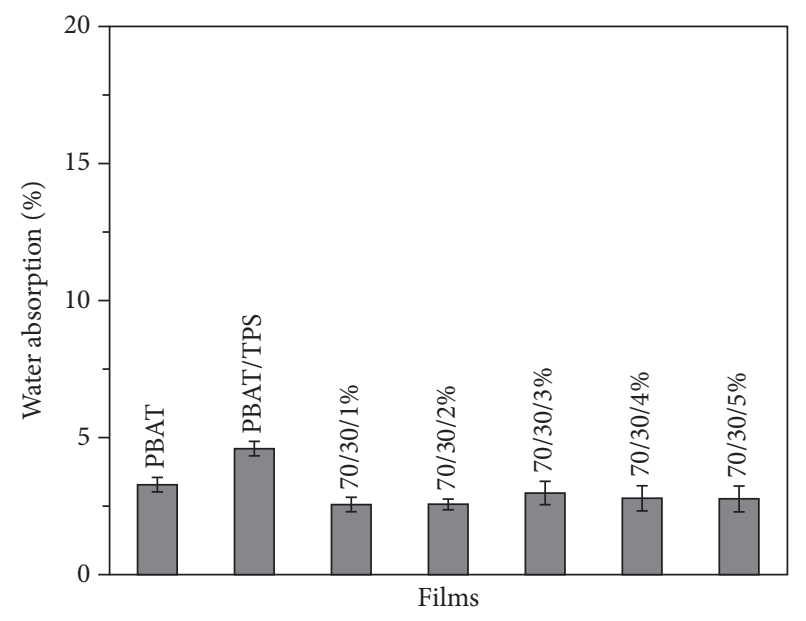

FIGURE 9: Water absorption of the films.

products. Depending on its end-use application, food packaging film must have the lowest possible WVP [48].

The incorporation of TPS into the PBAT matrix increased the WVP of the films $(p<0.05)$ significantly. This probably occurred due to the hydrophilic nature of the starch, favoring the intermolecular hydrogen bonding which can increase the water vapor diffusion through the film.

The WVP of all the films with SNP decreased significantly $(p<0.05)$ when compared to those of the PBAT films and PBAT/TPS. It was observed that films with SNP $(1 \mathrm{w} / \mathrm{w} \%)$ showed an approximate 53\% WVP reduction because the starch nanoparticles tend to increase the compactness of the films. The presence of SNP probably made the path for water molecules to pass through more tortuous [25].

As regards the opacity results, there were significant differences between all the films $(p<0.05)$; the PBAT film showed the lowest value (0.59) and the film with SNP $(4 \mathrm{w} / \mathrm{w} \%)$ the highest value (1.19). The opacity of a film indicates the amount of light that gets through it. Photosensitive food needs to be protected with high-opacity packaging [49].

3.7. Water Absorption Measurement. The water absorption of the films after storage at 55\% RH for 7 days is shown in Figure 9. The water absorption of PBAT film was 3.29\%; the PBAT is a hydrophobic polymer and therefore presents low water absorption [50]. The PBAT/TPS films presented larger water absorption capacity (4.61\%) when compared to PBAT films, with a significant difference between them $(p<0.05)$. This increase can be attributed to the hydrophilic character of starch [49].

For the films with SNP, the water absorption decreased when compared to PBAT and PBAT/TPS films with a significant difference $(p<0.05)$; the values obtained were $2.55 \%$, $2.58 \%, 2.99 \%, 2.79 \%$, and $2.78 \%$ for samples with $1-5 \mathrm{w} / \mathrm{w} \%$ of the SNP, respectively. These results could be explained by the fact that the nanoparticles improve the homogeneity and compactness of the polymeric structure, reducing the penetration of water and consequently its absorption. 
TABLE 1: Values of thickness, water vapor permeability (WVP), and opacity of the films.

\begin{tabular}{lccr}
\hline Sample & Thickness $(\mathrm{mm})$ & WVP $\left(10^{-8}\right)\left(\mathrm{g}^{-1}\right.$ Pa s m $)$ & Opacity $(\%)$ \\
\hline PBAT & $0.0913 \pm 0.0011^{\mathrm{a}}$ & $7.55 \pm 9.87 \times 10^{-10 \mathrm{~b}}$ & $0.59 \pm 0.0001^{\mathrm{g}}$ \\
PBAT/TPS & $0.1085 \pm 0.0041^{\mathrm{a}}$ & $9.89 \pm 5.52 \times 10^{-11 \mathrm{a}}$ & $0.74 \pm 0.0013^{\mathrm{d}}$ \\
$70 / 30 / 1 \%$ & $0.0769 \pm 0.0057^{\mathrm{a}}$ & $3.50 \pm 5.83 \times 10^{-10 \mathrm{c}}$ & $1.09 \pm 0.0032^{\mathrm{b}}$ \\
$70 / 30 / 2 \%$ & $0.1094 \pm 0.0044^{\mathrm{a}}$ & $4.09 \pm 2.17 \times 10^{-10 \mathrm{c}}$ & $0.82 \pm 0.0056^{\mathrm{e}}$ \\
$70 / 30 / 3 \%$ & $0.0737 \pm 0.0005^{\mathrm{a}}$ & $3.32 \pm 7.64 \times 10^{-10 \mathrm{c}}$ & $0.78 \pm 0.0007^{\mathrm{c}}$ \\
$70 / 30 / 4 \%$ & $0.0740 \pm 0.0005^{\mathrm{a}}$ & $3.66 \pm 1.17 \times 10^{-9 \mathrm{c}}$ & $1.19 \pm 0.0023^{\mathrm{a}}$ \\
$70 / 30 / 5 \%$ & $0.0833 \pm 0.0131^{\mathrm{a}}$ & $4.02 \pm 2.76 \times 10^{-10 \mathrm{c}}$ & $0.75 \pm 0.0011^{\mathrm{f}}$ \\
\hline
\end{tabular}

*Values with different letters in the same column are significantly different $(p<0.05)$.

TABLE 2: Mechanical properties of PBAT, PBAT/TPS, and PBAT/TPS/SNP films.

\begin{tabular}{lccr}
\hline Sample & $E(\mathrm{MPa})$ & $\mathrm{TS}(\mathrm{MPa})$ & $\mathrm{Eb}(\%)$ \\
\hline PBAT & $67.00 \pm 1.63^{\mathrm{cd}}$ & $9.33 \pm 0.47^{\mathrm{bc}}$ & $214.00 \pm 2.94^{\mathrm{bc}}$ \\
PBAT/TPS & $56.00 \pm 0.81^{\mathrm{d}}$ & $7.33 \pm 0.47^{\mathrm{c}}$ & $168.33 \pm 4.64^{\mathrm{d}}$ \\
$70 / 30 / 1 \%$ & $76.66 \pm 2.05^{\mathrm{bc}}$ & $9.33 \pm 0.47^{\mathrm{bc}}$ & $227.33 \pm 1.24^{\mathrm{a}}$ \\
$70 / 30 / 2 \%$ & $80.00 \pm 1.63^{\mathrm{ab}}$ & $11.24 \pm 0.47^{\mathrm{ab}}$ & $221.66 \pm 4.92^{\mathrm{ab}}$ \\
$70 / 30 / 3 \%$ & $81.33 \pm 4.02^{\mathrm{ab}}$ & $11.33 \pm 0.81^{\mathrm{ab}}$ & $217.00 \pm 0.94^{\mathrm{ab}}$ \\
$70 / 30 / 4 \%$ & $86.66 \pm 1.24^{\mathrm{ab}}$ & $11.00 \pm 0.85^{\mathrm{ab}}$ & $210.00 \pm 1.24^{\mathrm{bc}}$ \\
$70 / 30 / 5 \%$ & $87.66 \pm 7.31^{\mathrm{ab}}$ & $11.33 \pm 0.94^{\mathrm{ab}}$ & $202.33 \pm 4.92^{\mathrm{c}}$ \\
\hline
\end{tabular}

${ }^{*}$ Values with different letters in the same column are significantly different $(p<0.05)$.

3.8. Mechanical Properties. In Table 2, the results of Young's modulus $(E)$, tensile strength (TS), and elongation-at-break (Eb) of the films are presented. As can be seen, Young's modulus of the PBAT films was $67 \mathrm{MPa}$, elongation-at-break was $214 \%$, and tensile strength (TS) was $9.33 \mathrm{MPa}$. The incorporation of starch in the films $(70 / 30$ film) resulted in decreasing values of $E(\sim 17 \%)$, TS ( 21\%), and $\mathrm{Eb}(22 \%)$. The presence of some starch grains that were not completely ruptured during the extrusion process of the films (Figure 2(b)) explains such behavior. Starch granules can tease fissures that do not favor the interaction between the carbonyl group of the PBAT matrix and the starch [45].

The addition of $1 \%$ of SNP leads to a significant increase $(p<0.05)$ of $E(36 \%)$ and $\mathrm{Eb}(35 \%)$ of the films, when compared to the PBAT/TPS film. The addition of $2-5 \mathrm{w} / \mathrm{w} \%$ SNP did not improve the Young's modulus parameter significantly $(p>0.05)$. The Eb behavior for PBAT/TPS/SNP films with $1-3 \% \mathrm{w} / \mathrm{w}$ of SNP is similar to a better elongation effect when compared to the PBAT/TPS films. Such behavior can be attributed to interactions among the carbonyl groups of PBAT and the hydroxyl groups of the SNP and starch grains contributing to obtaining a more homogeneous film. The nanoparticles can fill the voids, improving the plasticization of the film. The work in [22] investigated the effect of $0.6 \%$ of SNP produced by Gamma radiation on a PBAT/TPS blend. The authors concluded that the incorporation of SNP in the polymer matrix improves $E$ and $\mathrm{Eb}$ of the composite.

However, it was observed that films with SNP ( $\geq 4 \mathrm{w} / \mathrm{w} \%)$ resulted in reduced values $(p<0.05)$ of Eb. In this work, we found that a high concentration of SNP can produce a rigid hydrogen bond network between SNP and starch, and this weakens the stress distribution, which hinders the elongation of the films [51].
Analyzing the behavior of the tensile strength for the PBAT/TPS films, it can be seen that the incorporation of $1 \%$ of SNP led to a slight increase in the TS, but this was not significant $(p>0.05)$. However, the incorporation of $2-5 \mathrm{wt} \%$ SNP in the films resulted in significantly $(p<$ 0.05) improved values. The work in [25] claims that the interaction between TPS and SNP is favored due to their molecular structure and chemical nature, which facilitates the production of homogeneous films with good mechanical properties.

\section{Conclusions}

Starch nanoparticles were successfully prepared using the physical method of high-intensity ultrasonication without any chemical additives. XRD analysis showed the amorphous character nanoparticles. The thermal analysis showed that the SNP are more thermally instable and have a lower gelatinization temperature when compared to starch.

The incorporation of SNP did not modify the morphology of the PBAT/TPS films. However, decreased relative crystallinity occurred with the increase in the SNP concentration in the films.

The TGA showed that the SNP induced a displacement of the degradation temperature of the first event. DSC analysis revealed that the SNP did not cause any change in the $T_{\mathrm{g}}$ and $T_{\mathrm{m}}$ films. The opacity values differed in all films.

With the addition of starch to PBAT matrix, all the tensile parameters exhibit slight decreases and an increase in the WVP of the films. Incorporation of only 1\% SNP in a PBAT/TPS matrix produced films with better properties ( $E, \mathrm{~Eb}, \mathrm{WVP}$, and water absorption) than PBAT films. As a result, blends of PBAT/TPS/SNP are an interesting option 
for developing environmentally friendly and energy-saving packaging materials at a low cost.

\section{Conflicts of Interest}

The authors declare that there are no conflicts of interest regarding the publication of this paper.

\section{Acknowledgments}

The authors acknowledge the Engineering and Polymerization Laboratory (EngePol) at Federal University of Rio de Janeiro (UFRJ) and Gonçalo Moniz Research Center, FIOCRUZ, Salvador, BA, for their assistance in the analysis.

\section{References}

[1] G. E. Luckachan and C. K. S. Pillai, "Biodegradable polymers- a review on recent trends and emerging perspectives," Journal of Polymers and the Environment, vol. 19, no. 3, pp. 637-676, 2011.

[2] C. M. O. Müller, J. B. Laurindo, and F. Yamashita, "Composites of thermoplastic starch and nanoclays produced by extrusion and thermopressing," Carbohydrate Polymers, vol. 89, no. 2, pp. 504-510, 2012.

[3] N. R. Savadekar and S. T. Mhaske, "Synthesis of nano cellulose fibers and effect on thermoplastics starch based films," Carbohydrate Polymers, vol. 89, no. 1, pp. 146-151, 2012.

[4] P. Sarazin, G. Li, W. J. Orts, and B. D. Favis, "Binary and ternary blends of polylactide, polycaprolactone and thermoplastic starch," Polymer Journal, vol. 49, no. 2, pp. 599-609, 2008.

[5] M. Thunwall, V. Kuthanová, A. Boldizar, and M. Rigdahl, "Film blowing of thermoplastic starch," Carbohydrate Polymers, vol. 71, no. 4, pp. 583-590, 2008.

[6] H. Angellier, S. Molina-Boisseau, P. Dole, and A. Dufresne, "Thermoplastic starch- waxy maize starch nanocrystals nanocomposites," Biomacromolecules, vol. 7, no. 2, pp. 531-539, 2006.

[7] J. B. Olivato, C. M. O. Müller, F. Yamashita, M. V. E. Grossmann, and M. M. Nobrega, "Study of the compatibilizer effect in the properties of starch/polyester blends," Polímeros, vol. 23, no. 3, pp. 346-351, 2013.

[8] V. A. D. Marinho, C. A. B. Pereira, M. B. C. Vitorino, A. S. Silva, L. H. Carvalho, and E. L. Canedo, "Degradation and recovery in poly(butylene adipate-co-terephthalate)/ thermoplastic starch blends," Polymer Testing, vol. 58, pp. 166-172, 2017.

[9] D. Chen, D. Lawton, M. R. Thompson, and Q. Liu, "Biocomposites reinforced with cellulose nanocrystals derived from potato peel waste," Carbohydrate Polymers, vol. 90, no. 1, pp. 709-716, 2012.

[10] A.-L. Goffin, J.-M. Raquez, E. Duquesne et al., "From interfacial ring-opening polymerization to melt processing of cellulose nanowhisker-filled polylactide-based nanocomposites," Biomacromolecules, vol. 12, no. 7, pp. 2456-2465, 2011.

[11] H.-Y. Yu, Z.-Y. Qin, Y.-N. Liu, L. Chen, N. Liu, and Z. Zhou, "Simultaneous improvement of mechanical properties and thermal stability of bacterial polyester by cellulose nanocrystals," Carbohydrate Polymers, vol. 89, no. 3, pp. 971-978, 2012.

[12] S. Bel Haaj, W. Thielemans, A. Magnin, and S. Boufi, "Starch nanocrystals and starch nanoparticles from waxy maize as nanoreinforcement: A comparative study," Carbohydrate Polymers, vol. 143, pp. 310-317, 2016.
[13] Y. Chang, X. Yan, Q. Wang, L. Ren, J. Tong, and J. Zhou, "High efficiency and low cost preparation of size controlled starch nanoparticles through ultrasonic treatment and precipitation," Food Chemistry, vol. 227, pp. 369-375, 2017.

[14] Y. Qin, C. Liu, S. Jiang, L. Xiong, and Q. Sun, "Characterization of starch nanoparticles prepared by nanoprecipitation: Influence of amylose content and starch type," Industrial Crops \& Products, vol. 87, pp. 182-190, 2016.

[15] X. Ma, R. Jian, P. R. Chang, and J. Yu, "Fabrication and characterization of citric acid-modified starch nanoparticles/ plasticized-starch composites," Biomacromolecules, vol. 9, no. 11, pp. 3314-3320, 2008.

[16] H.-Y. Kim, S. S. Park, and S.-T. Lim, "Preparation, characterization and utilization of starch nanoparticles," Colloids and Surfaces B: Biointerfaces, vol. 126, pp. 607-620, 2015.

[17] S. Bel Haaj, A. Magnin, C. Pétrier, and S. Boufi, "Starch nanoparticles formation via high power ultrasonication," Carbohydrate Polymers, vol. 92, no. 2, pp. 1625-1632, 2013.

[18] H.-Y. Kim, D. J. Park, J.-Y. Kim, and S.-T. Lim, "Preparation of crystalline starch nanoparticles using cold acid hydrolysis and ultrasonication," Carbohydrate Polymers, vol. 98, no. 1, pp. 295301, 2013.

[19] Q. Sun, H. Fan, and L. Xiong, "Preparation and characterization of starch nanoparticles through ultrasonic-assisted oxidation methods," Carbohydrate Polymers, vol. 106, no. 1, pp. 359-364, 2014.

[20] P. M. Gonçalves, C. P. Z. Noreña, N. P. da Silveira, and A. Brandelli, "Characterization of starch nanoparticles obtained from Araucaria angustifolia seeds by acid hydrolysis and ultrasound," LWT-Food Science and Technology, vol. 58, no. 1, pp. 21-27, 2014.

[21] D. Le Corre and H. Angellier-Coussy, "Preparation and application of starch nanoparticles for nanocomposites: A review," Reactive and Functional Polymers, vol. 85, pp. 97-120, 2014.

[22] P. G. Seligra, L. E. Moura, L. Famá, J. I. Druzian, and S. Goyanes, "Influence of incorporation of starch nanoparticles in PBAT/TPS composite films," Polymer International, vol. 65, no. 8, pp. 938-945, 2016.

[23] J. B. Silva, J. I. Druzian, F. V. Pereira et al., "Processo

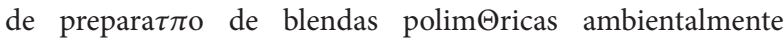
degradßveis refor $\tau$ adas com nanocristais de celulose (nanocelulose) para produ $\tau \pi \mathrm{o}$ de filmes flex $\varphi$ veis por extrus $\pi \mathrm{o}, " B R$ Patent INPI, Article ID 011120000389, 2012.

[24] S. Nara and T. Komiya, "Studies on the relationship between water-satured state and crystallinity by the diffraction method for moistened potato starch," Starch - Stärke, vol. 35, no. 12, pp. 407-410, 1983.

[25] A.-M. Shi, L.-J. Wang, D. Li, and B. Adhikari, "Characterization of starch films containing starch nanoparticles Part 1: Physical and mechanical properties," Carbohydrate Polymers, vol. 96, no. 2, pp. 593-601, 2013.

[26] M.-F. Huang, J. G. Yu, and X. F. Ma, "Studies on the properties of Montmorillonite-reinforced thermoplastic starch composites," Polymer Journal, vol. 45, no. 20, pp. 7017-7023, 2004.

[27] X. F. Ma, J. G. Yu, and N. Wang, "Fly ash-reinforced thermoplastic starch composites," Carbohydrate Polymers, vol. 67, no. 1, pp. 32-39, 2007.

[28] K. Kaewtatip and J. Thongmee, "Effect of kraft lignin and esterified lignin on the properties of thermoplastic starch," Materials and Design, vol. 49, pp. 701-704, 2013.

[29] S. Rezende, S. Stanisçuaski, L. De Lucca, and A. Raffin, Revis $\pi$, vol. 26, no. 5, pp. 726-737, 2003. 
[30] M. R. Avadi, A. M. M. Sadeghi, N. Mohammadpour et al., "Preparation and characterization of insulin nanoparticles using chitosan and Arabic gum with ionic gelation method," Nanomedicine: Nanotechnology, Biology and Medicine, vol. 6, no. 1, pp. e58-e63, 2010.

[31] S. B. Haaj, A. Magnin, and S. Boufi, "Starch nanoparticles produced via ultrasonication as a sustainable stabilizer in Pickering emulsion polymerization," RSC Advances, vol. 4, no. 80, pp. 42638-42646, 2014.

[32] D. Liu, Q. Wu, H. Chen, and P. R. Chang, "Transitional properties of starch colloid with particle size reduction from micro- to nanometer," Journal of Colloid and Interface Science, vol. 339, no. 1, pp. 117-124, 2009.

[33] J. B. Olivato, J. Marini, E. Pollet, F. Yamashita, M. V. E. Grossmann, and L. Avérous, "Elaboration, morphology and properties of starch/polyester nano-biocomposites based on sepiolite clay," Carbohydrate Polymers, vol. 118, pp. 250-256, 2015.

[34] S. K. Nayak, "Biodegradable PBAT/Starch nanocomposites," Polymer-Plastics Technology and Engineering, vol. 49, no. 14, pp. 1406-1418, 2010.

[35] J. J. G. Van Soest and J. F. G. Vliegenthart, "Crystallinity in starch plastics: consequences for material properties," Trends in Biotechnology, vol. 15, no. 6, pp. 208-213, 1997.

[36] E. Cranston, J. Kawada, S. Raymond, F. G. Morin, and R. H. Marchessault, "Cocrystallization model for synthetic biodegradable poly(butylene adipate-co-butylene terephthalate)," Biomacromolecules, vol. 4, no. 4, pp. 995-999, 2003.

[37] J.-M. Raquez, Y. Nabar, R. Narayan, and P. Dubois, "In situ compatibilization of maleated thermoplastic starch/polyester melt-blends by reactive extrusion," Polymer Engineering \& Science, vol. 48, no. 9, pp. 1747-1754, 2008.

[38] R. A. L. Santos, C. M. O. Muller, M. V. E. Grossmann, S. Mali, and F. Yamashita, "Starch/poly (butylene adipate-coterephthalate)/montmorillonite films produced by blow extrusion," Química Nova, vol. 37, no. 6, pp. 937-942, 2014.

[39] N. L. García, M. Lamanna, N. D’Accorso, A. Dufresne, M. Aranguren, and S. Goyanes, "Biodegradable materials from grafting of modified PLA onto starch nanocrystals," Polymer Degradation and Stability, vol. 97, no. 10, pp. 2021-2026, 2012.

[40] M. Lamanna, N. J. Morales, N. L. Garcia, and S. Goyanes, "Development and characterization of starch nanoparticles by gamma radiation: Potential application as starch matrix filler," Carbohydrate Polymers, vol. 97, no. 1, pp. 90-97, 2013.

[41] N. L. García, L. Famá, A. Dufresne, M. Aranguren, and S. Goyanes, "A comparison between the physico-chemical properties of tuber and cereal starches," Food Research International, vol. 42, no. 8, pp. 976-982, 2009.

[42] F. Zhu, "Impact of ultrasound on structure, physicochemical properties, modifications, and applications of starch," Trends in Food Science \& Technology, vol. 43, no. 1, pp. 1-17, 2015.

[43] A. R. Jambrak, Z. Herceg, D. Subaric et al., "Ultrasound effect on physical properties of corn starch," Carbohydrate Polymers, vol. 79, no. 1, pp. 91-100, 2010.

[44] J. Huang, H. A. Schols, J. J. G. Van Soest, Z. Jin, E. Sulmann, and A. G. J. Voragen, "Physicochemical properties and amylopectin chain profiles of cowpea, chickpea and yellow pea starches," Food Chemistry, vol. 101, no. 4, pp. 1338-1345, 2007.

[45] S. Mohanty and S. K. Nayak, "Starch based biodegradable PBAT nanocomposites: Effect of starch modification on mechanical, thermal, morphological and biodegradability behavior," International Journal of Plastics Technology, vol. 13, no. 2, pp. 163-185, 2009.

[46] M. Kumar, S. Mohanty, S. K. Nayak, and M. R. Parvaiz, "Effect of glycidyl methacrylate (GMA) on the thermal, mechanical and morphological property of biodegradable PLA/PBAT blend and its nanocomposites," Bioresource Technology, vol. 101, no. 21, pp. 8406-8415, 2010.

[47] R. Al-Itry, K. Lamnawar, A. Maazouz, N. Billon, and C. Combeaud, "Effect of the simultaneous biaxial stretching on the structural and mechanical properties of PLA, PBAT and their blends at rubbery state," European Polymer Journal, vol. 68, pp. 288-301, 2015.

[48] I. F. E. Silva, F. Yamashita, C. M. O. Müller et al., "How reactive extrusion with adipic acid improves the mechanical and barrier properties of starch/poly (butylene adipate-co-terephthalate) films," International Journal of Food Science \& Technology, vol. 48, no. 8, pp. 1762-1769, 2013.

[49] H. M. Chen, Q. Huang, X. Fu, and F.-X. Luo, "Ultrasonic effect on the octenyl succinate starch synthesis andsubstitution patterns in starch granules," Food Hydrocolloids, vol. 35, pp. 636643, 2014.

[50] R. P. H. Brandelero, M. V. Grossmann, and F. Yamashita, "Films of starch and poly(butylene adipate co-terephthalate) added of soybean oil (SO) and Tween 80," Carbohydrate Polymers, vol. 90, no. 4, pp. 1452-1460, 2012.

[51] S. Jiang, C. Liu, X. Wang, L. Xiong, and Q. Sun, "Physicochemical properties of starch nanocomposite films enhanced by selfassembled potato starch nanoparticles," LWT- Food Science and Technology, vol. 69, pp. 251-257, 2016. 

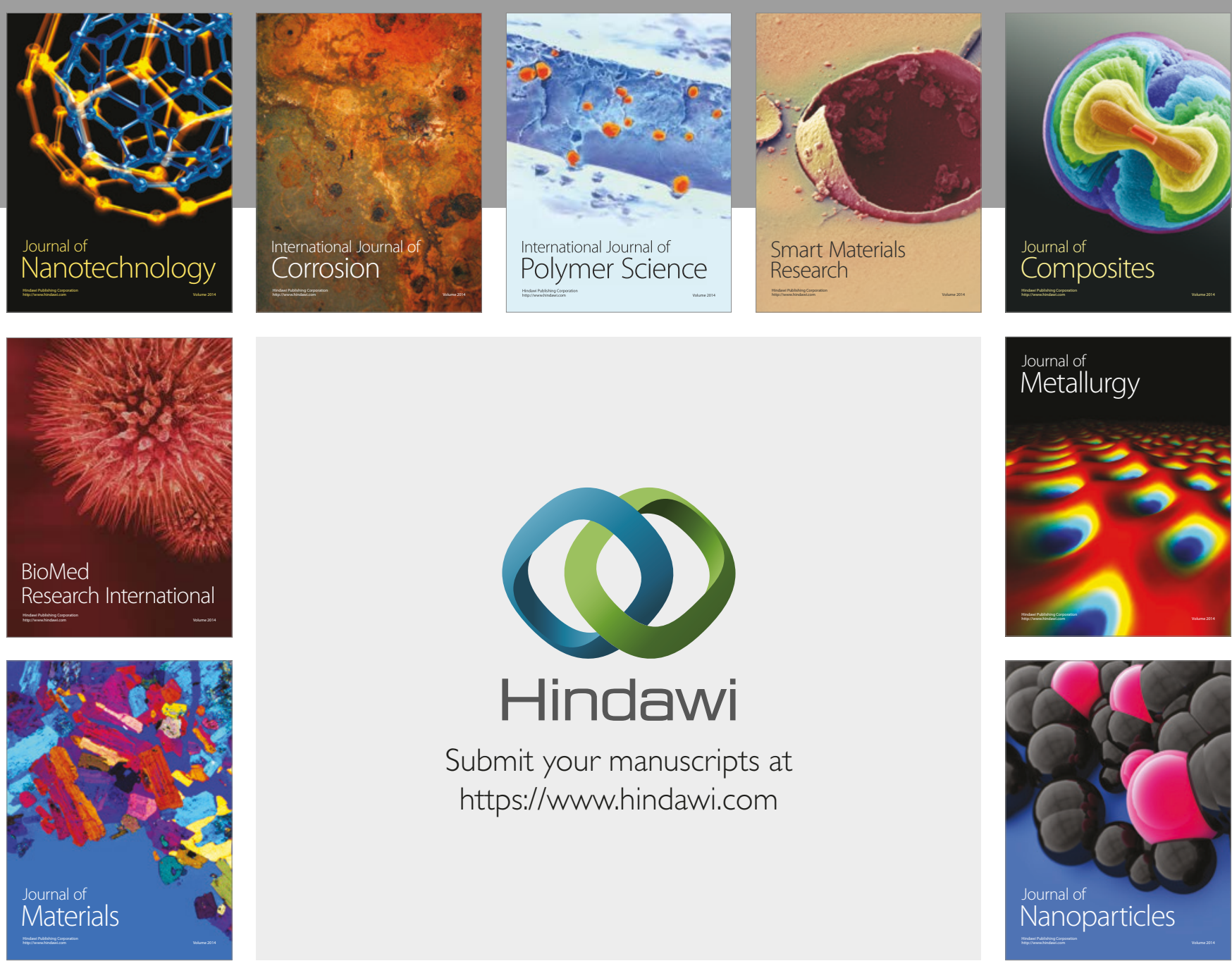

\section{Hindawi}

Submit your manuscripts at

https://www.hindawi.com
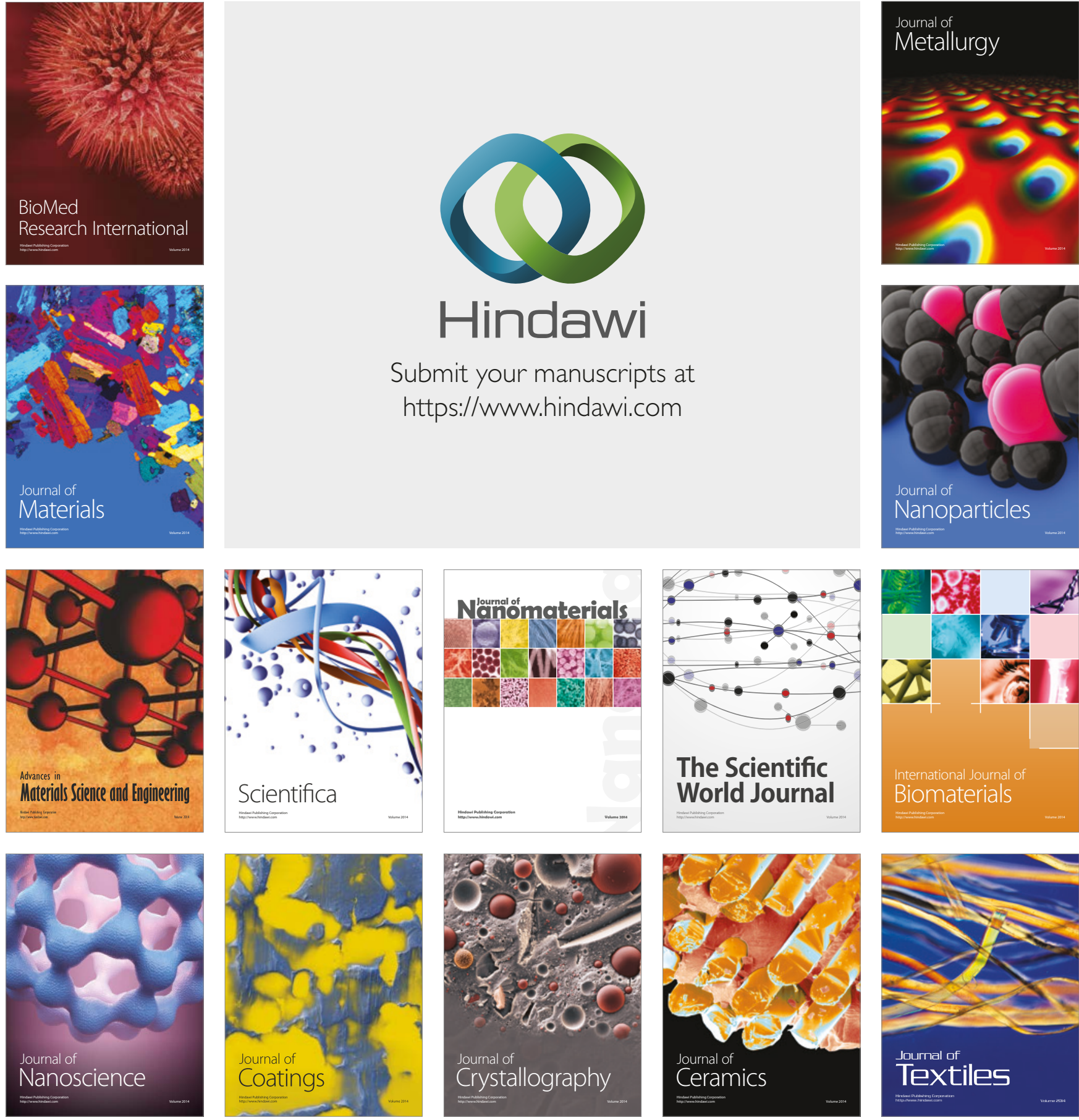

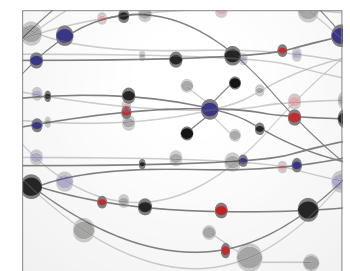

The Scientific World Journal
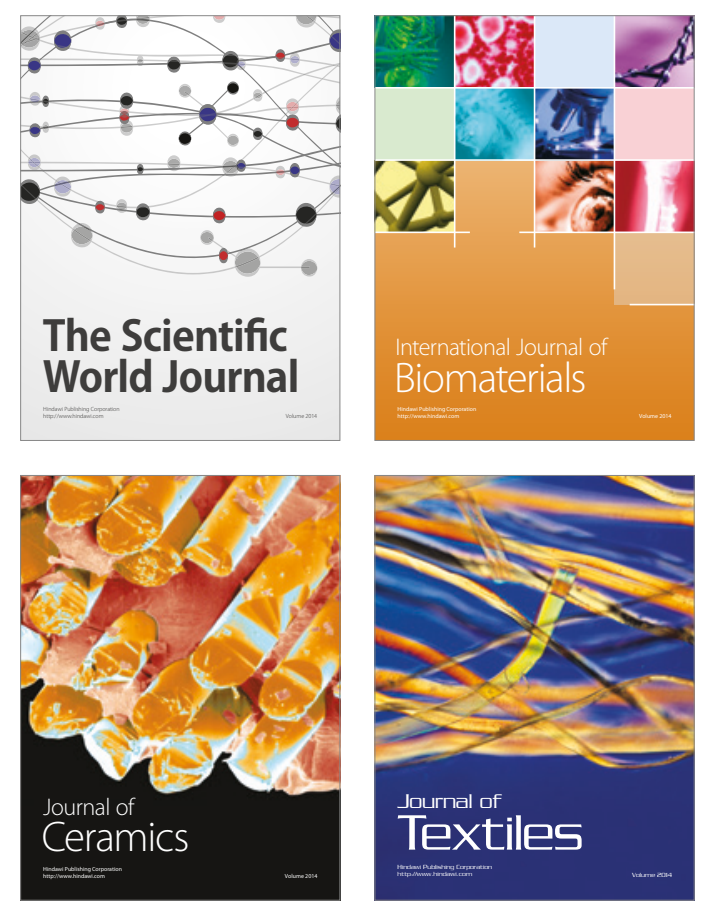